neurotic to incapable?

These three example treatments illustrate the complexities of our responsibilities. The readership may hope for early classification outside the Law Courts. To do our best and be wrong is bad enough, but to do our best to a patient who is sure we are wrong, and be wrong, is worse, and in such circumstances it is even more difficult to be right. On the other hand we are presented with the problems in such circumstances, and we have to handle them.

J. A. Flowerdew

Shrewsbury Hospital

Bicton Heath, Shrewsbury

\section{Sorting out the confusion in psychiatric day care DeAr SiR}

Philip Vaughan, in his recent article (Bulletin, October $1983,7,184-5)$, rightly highlights the current confusion over the functions of psychiatric day care in this country. However, there is, in fact, evidence in the literature which could dispel the confusion.

There are numerous studies demonstrating the value of day hospital care as an alternative to in-patient admission, ${ }^{1,2,3}$ although none is as impressive as the study Vaughan cites. ${ }^{4}$

Family burden has been specifically investigated in an important controlled study by Herz and colleagues in the United States, in which day care was used in conjunction with a policy of brief hospital admission for acutely ill patients. ${ }^{5}$ Burden was lower for the families of patients offered a combination of brief in-patient admission and transitional day care than for families of those offered standard (prolonged) in-patient treatment. Similar findings are reported by Hirsch in the UK.6 Turning to day care for the chronic (psychiatric) patient, there is abundant evidence as to its utility in both improving the quality of life and preventing relapse in schizophrenic patients.' Interestingly, the most effective units are those concentrating on 'recreational' rather than 'therapeutic' activities.

Much less researched is the use of day care for neurotic illnesses. However, one controlled study showed no advantage of day care as opposed to out-patient treatment for newlypresenting neurotic patients. ${ }^{8}$ Its authors concluded that outpatient treatment was to be preferred. (There is, however, evidence that for chronic neurotic disorders a community psychiatric nursing service may be preferable to psychiatric out-patient care.')

One reason for the difficulty in rationally planning psychiatric day care within a district is the artificial distinction between hospital and social service provision. There needs to be close communication between day hospitals and day centres, with the opportunity for interchange of both patients and skills between units. The need for communication also applies to residential facilities, as local authorities take on responsibility for many who, in the past, would have occupied a long-stay hospital bed.

Perhaps the future lies in a Mental Illness Service, distinct from both Health and Local Authorities.

King's College Hospital

Frank Holloway

Denmark Hill, London SES

\section{REFERENCES}

'Craft, M. (1958) An evaluation of treatment of depressive illnesses in a day hospital. Lancet, ii, 149-51.

${ }^{2}$ Penk, W. E., Charles, H. L., \& Van Hoose, T. A. (1978) Comparative effectiveness of day hospital and inpatient psychiatric treatment. Journal of Consulting and Clinical Psychology, 46, 94-101.

${ }^{3}$ ZWERLNG, I. WIIDER, J. F. (1966) An evaluation of the applicability of the day hospital in the treatment of acutely disturbed patients. Israel Annals of Psychiatry, 2, 162-85.

'Herz, M. I., Endicott, J., Spitzer, R. L. \& Mesnikoff, A. (1971) Day versus inpatient hospitalization: A controlled study. American Journal of Psychiatry, 127, 1371-82.

___ \& GrBson, M. (1979) Brief hospitalization: Twoyear follow-up. Archives of General Psychiatry, 36, 701-5.

'Hirsch, S. R., Platt, J., Knights, A. \& Weyman, A. (1979) Shortening hospital stay for psychiatric care: Effects on patients and their families. British Medical Journal, $i$, 442-6.

'Linn, M. W., Cappey, E. M., Klett, J., Hogarty, G. E. \& Lamb, H. R. (1979) Day treatment and psychotropic drugs in the after care of schizophrenic patients. Archives for General Psychiatry, 36, 1005-1066.

'TYReR, P. J. \& Remington, M. (1979) Controlled comparison of day hospital and outpatient treatment for neurotic disorders. Lancet, $i, 1014-16$.

'PAykel, E. S., Mangen, S. P., Gripftth, J. H. \& Burns, T. P. (1982) Community psychiatric nursing for neurotic patients: A controlled trial. British Journal of Psychiatry, 140, 573-81.

\section{DeAr Sir}

Phillip J. Vaughan (Bulletin, October 1983, 7, 184-5) rightly draws attention to the confusion surrounding day care. He points to the enormous variety of kinds of day hospital serving almost every kind of patient, and observes that day hospitals frequently offer treatment that is hardly different from that offered in nearby in-patient units. The style often reflects the ideas and personality of the consultant in charge rather than 'a systematized part of a complete whole'. However, exactly the same comments can be made about in-patient care.

There is very little research of an adequate standard addressing the questions that Mr Vaughan raises, so units are bound to evolve according to hunch and habit. Braun $e t$ al.' reviewed controlled outcome studies of alternatives to hospital admission, modifications of conventional hospitalization, and alternatives to long-term hospitalization for the period 1966 to 1978 . They found only two studies of day care, seven studies of other alternatives to hospital admission, and six studies of modifications of hospital admission. 
The methodological problems of designing such studies are considerable. Selecting criteria for the control condition is particularly difficult. 'Standard hospital care' has been used in a number of studies but, as Braun et al point out, this differs greatly from place to place and is extremely difficult to characterize. Defining the patient population studied is no easier. Diagnosis is a very poor predictor of disposal. Some workers ${ }^{2}$ have used a psychiatric opinion that the patients 'required admission' as a key criterion for admission to the study, but there is evidence that this is far from reliable. For example, Mendel $e t a \beta$ found that it depended on the experience of the doctor making the decision and whether the patient arrived at the clinic after hours. Feigelson et af found that it depended on the facilities and staffing of the emergency clinic. The patient's clinical state is far from being the only factor that determines the judgement that the patient requires admission. Also, there have been two studies in which patients judged to require admission have been randomly allocated (with very few exceptions) to treatment in hospital or at home, 5,6 and in both studies most of the patients allocated to home were treated there successfully. This further questions the usefulness of the criterion.

It will be a long time before we are able to allocate patients to in-patient, out-patient, or day care according to wellresearched criteria. Until then it will have to be done intuitively. I suggest that the careful study of the factors that influence those intuitive decisions may suggest better ways of selecting patients. That would be an important step towards answering some of the pressing questions Mr Vaughan raises.

90 Baronshill Avenue Linlithgow, West Lothian

REFERENCES

'Braun, P., Kochansky, G., Shapiro, R., Greenberg, S. Gudman, J. G., Johnson, S. \& SHORE, M. F. (1981) Overview: Deinstitutionalization of psychiatric patients; a critical review of outcome studies. American Journal of Psychiatry, 136, 736-49.

2BARTolucci, G. \& Drayer, C. (1973) An overview of crisis intervention in the emergency rooms of general hospitals. American Journal of Psychiatry, 130, 953-60.

'MENDEL, W. \& RAPPORT, S. (1969) Determinants of the decision for psychiatric hospitalization. Archives of General Psychiatry, 20, 321-8.

'Feigelson, E. B., Davis, E. B., Mackinnon, R., Shands, H. C. \& SCHWARTZ, C. C. (1978) Decision to hospitalize. American Journal of Psychiatry, 135, 354-7.

'STEIN, L. I. \& Test, M. A. (1980) Alternative to mental hospital treatment: 1. Conceptual model, treatment program and clinical evaluation. Archives of General Psychiatry, 37, 392-7.

'Hoult, J., Reynolds, I., Charbonneau-Powis, M., Weekes, P. \& BRIGGs, J. (1983) Psychiatric hospital versus community treatment: the results of a randomized trial. Australian and New Zealand Journal of Psychiatry, 17, 160-7.

\section{DeAr SIR}

Whilst we agree with Mr Vaughan's (Bulletin, October 1983, 7, 184-5) wish for more planned research and evaluation in the field of day care, we find the negative viewpoint of this article disturbing. There are to be found in it the same sweeping generalizations and untested assumptions of which he is so critical, and one is left wondering what Mr Vaughan actually wants from day care.

On the one hand, Mr Vaughan criticizes the fact that day hospitals have developed in a diverse way, but then in conclusion praises the flexibility and uniqueness of day care. We would hope that this diversified range of services provided by day hospitals reflects the need of a particular community and patient population, rather than the ideas and personality of an omnipotent consultant.

Mr Vaughan feels that it is unfortunate that few day hospitals include the patient's family in the treatment process, but continuing in the vein of his article, what evidence has he to show that this would be beneficial? Of course, in the real world one tries to involve the family as much as is possible, but we cite this as an example of the confusion provoked by the article.

As nurses, we find his assumption that 'nursing staff transfer into day settings and simply bring institutional ideas with them' particularly insulting. It is this kind of sweeping generalization which does further damage to working relations between Social Services and health service staff and is demoralizing to nurses. Is he not aware of the fact that nurses in their training have had their theoretical knowledge and work experience in day care and community settings increased, as laid down by the UKCC? Furthermore, when qualified it is a positive decision for a nurse to move into day care. This move can be taken as a rejection of those same institutional ideas which $\mathrm{Mr}$ Vaughan claims nurses carry with them. Is he also aware of the ever increasing qualifications and experience required of a nurse for a post in day care? It seems not.

From his article it would seem that Mr Vaughan is unhappy about the way in which day care has developed and how its continuation is likely to be haphazard. Perhaps it would have been a more useful exercise for him to make positive suggestions on how the difficulties presented by the current system to researchers, could be overcome, rather than casting an air of pessimism over the day care services.

JuLe Connell

AdRIAN MUNSEY

Heatherwood Day Unit

King's Ride, Ascot, Berks

\section{Impressions of a locum at Belgrave Square DeAR Sir \\ Throughout September 1983 the British Journal of Psychiatry was without an editor, and I was informally} asked to be Acting Editor. The work was interesting and 